\title{
Case Report: Atypical Clinical and Radiological Presentation of Juvenile Nasopharyngeal Angiofibroma
}

\author{
Abdelrahman E. M. Ezzat ${ }^{1}$, Hussein M. Roshdy ${ }^{2}$ and Mustafa I. Eid ${ }^{3}$ \\ ${ }^{I}$ Associated lecture, (MBBCh, MSc, MRCS, DOHNS \& MBA-hosp.), ENT Department, Al-Azhar Faculty of \\ Medicine, Cairo, Egypt. \\ ${ }^{2}$ Lecture (MBBCh, MSc and MD), Diagnostic Radiology Department, Faculty of Medicine, Al-Azhar University- \\ Cairo-Egypt. \\ ${ }^{3}$ Associated lecture, (MBBCh \& MSc), ENT Department, Al-Azhar Faculty of Medicine, Cairo, Egypt.
}

\begin{abstract}
Juvenile nasopharyngeal angiofibroma (JNA) constitutes less than $0.5 \%$ of all head and neck neoplasm. It is a histopathologically benign, yet locally aggressive, vascular tumor that occurs most frequently in males from 5 to 25 years. However, it could mimic the clinical course of antrochoanal polyp. The clinical and radiological evaluated with computer tomography and with endoscopic resection of the tumor (an antrochoanal polyp), a histopathological report was angiofibroma.
\end{abstract}

Key words: Nasopharyngeal mass, Nasopharynx angiofibroma, antrochoanal polyp,

\section{Background}

Nasopharynx angiofibroma is a combined vascular and fibrous neoplasm arising in the nasopharynx of prepubertal and adolescent males. The tumor exhibits a strong tendency to bleed and, despite being microscopically benign, frequently exhibits destructive and aggressive behaviour.

\section{Histopathology}

Histologically, JNA exhibits cells of myofibroblast origin surrounded by a fibrous pseudocapsule. There are multiple vascular channels dispersed within the neoplasm composed of abundant endothelial cells embedded in a collagenous tissue network. An important hallmark is the lack of a true muscular layer, and this absence precludes any form of vasoconstriction and is felt to contribute to the tumor's high propensity for hemorrhage ${ }^{1}$.

\section{Diagnosis}

Key features to support a diagnosis of JNA include the presence of a vascular mass with an epicenter at the posterior nasal cavity near the medial pterygopalatine fossa, the presence of bony modeling-but not destruction - with tumor growth, and the lack of regional or distant metastasis. For atypical extension or unexpected rapid growth, a biopsy should be considered to assess for other neoplasms aside from JNA ${ }^{2}$.

The computed tomography (CT) and magnetic resonance imaging (MRI) are the primary diagnostic tests. JNA is commonly associated with known as the Holman-Miller sign. Widening of the sphenopalatine foramen may also be observed on CT and MR scanning offers improved soft tissue delineation. The tumour may display a "salt and pepper" appearance ${ }^{3}$.

Angiography is of diagnostic value with its characteristic tumour blush. It provides information about the major vascular supply and allows for pre-operative embolisation. The major arterial supply to these tumours is typically the ipsilateral internal maxillary artery, with occasional additional vessels from ascending pharyngeal artery, and branches from cavernous ICA or contra lateral external carotid system ${ }^{4}$.

\section{Clinical presentation}

Clinical presentation is usually with nasal obstruction or recurrent severe epistaxis in an adolescent male. Clinical features vary depending upon the extent of disease, but extensions into the sphenoid and other sinuses, orbit, infratemporal fossa and middle cranial fossa are often silent ${ }^{5,6}$. Alternately, such extensions may manifest with cheek swelling, proptosis or visual loss ${ }^{6}$.

\section{Treatment}

The primary treatment modality is surgical excision ${ }^{6}$ and it remains a viable option in cases of intracranial extension ${ }^{7,8}$. However, the surgical plan needs to consider that a more extensive resection in an attempt to prevent recurrence is inherently associated with a higher degree of morbidity. Areas of most concern include the pterygoid fossa, clivus, basisphenoid, sphenoid diploe, cavernous sinus, and intracranial vault ${ }^{9}$. 


\section{Case Report}

A 15-year-old boy was referred to our department from another hospital with difficulty in breathing and swallowing for 6 months. Over time, his complaint had increased. He had been complaining of nasal obstruction for a long time. There was no nasal discharge or allergic tendencies with only one episode of mild epistaxis occurred 2 months ago. The child was in good physical health with hyponasal speech. On examination of the oral cavity; there was a large, smooth surfaced, reddish mass hanging behind the soft palate into the hypopharynx. Anterior rhinoscopy was showing smooth surface whitish polyp, on rigid endoscopic examination of the nasal cavities and the nasopharynx, the same polyp.

On examination of the neck, there was no palpable lymph node. Computerized tomography (CT) of the paranasal sinuses demonstrated free sinuses with tumor extends from the right pneumatised pterygoid air cell into nasopharynx and continuing into the oral cavity (Fig. 1 A\&B).

Tumor extends from the right pneumatised pterygoid air cell into nasopharynx and continuing into the nasal cavity on the right side (Fig. 2 A\&B). The patient was operated under general anesthesia, in the supine position with his head slightly elevated, a pedicle of the polyp on the lateral nasal wall passing through the right choana into the nasopharynx, the pedicle of the polyp at level below the middle turbinate. The tumour removed complete endoscopically (Fig. 3).

A nasal packing mirocele ${ }^{\circledR}$ was used. The histopathological examination showed features of a nasopharyngeal angiofibroma with highly fibrous elements. The outcome of surgery was evaluated clinically, endoscopic and by CT scans.
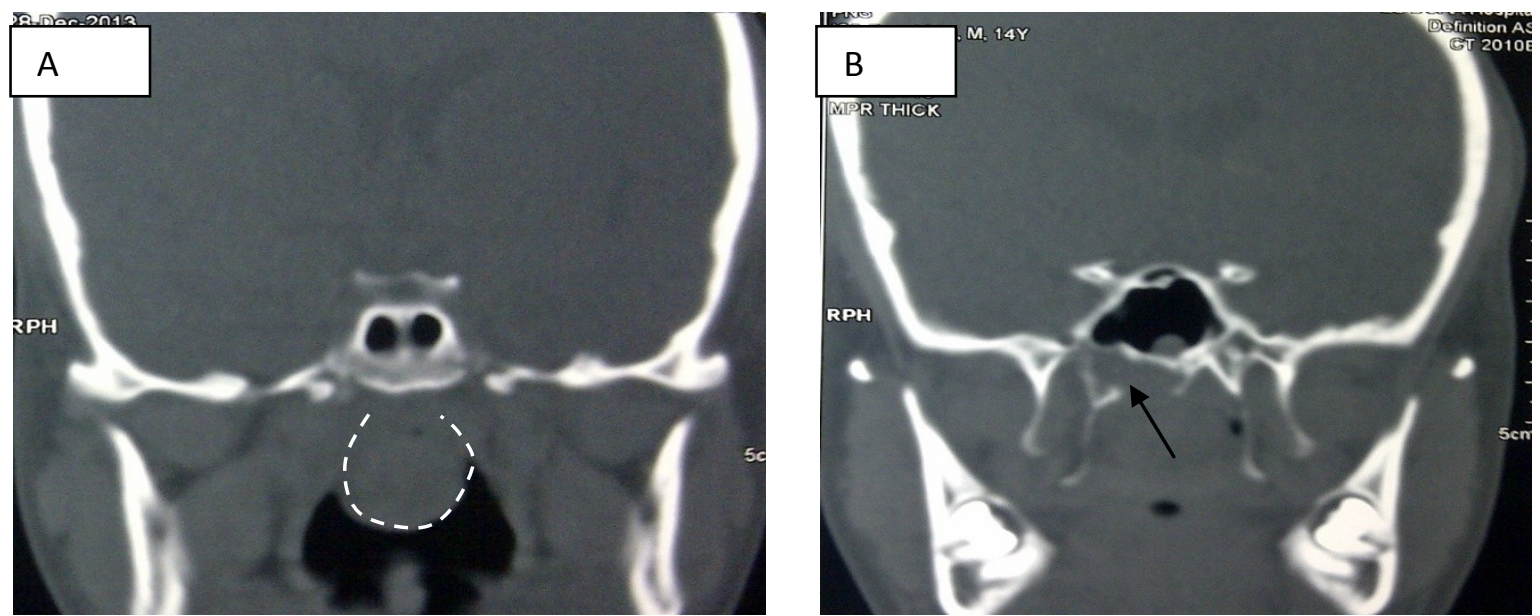

Figure 1 A\&B: Cronal CT image: Tumor extends from the right pneumatised pterygoid air cell (the arrow) into nasopharynx and continuing into the oral cavity (dots line).
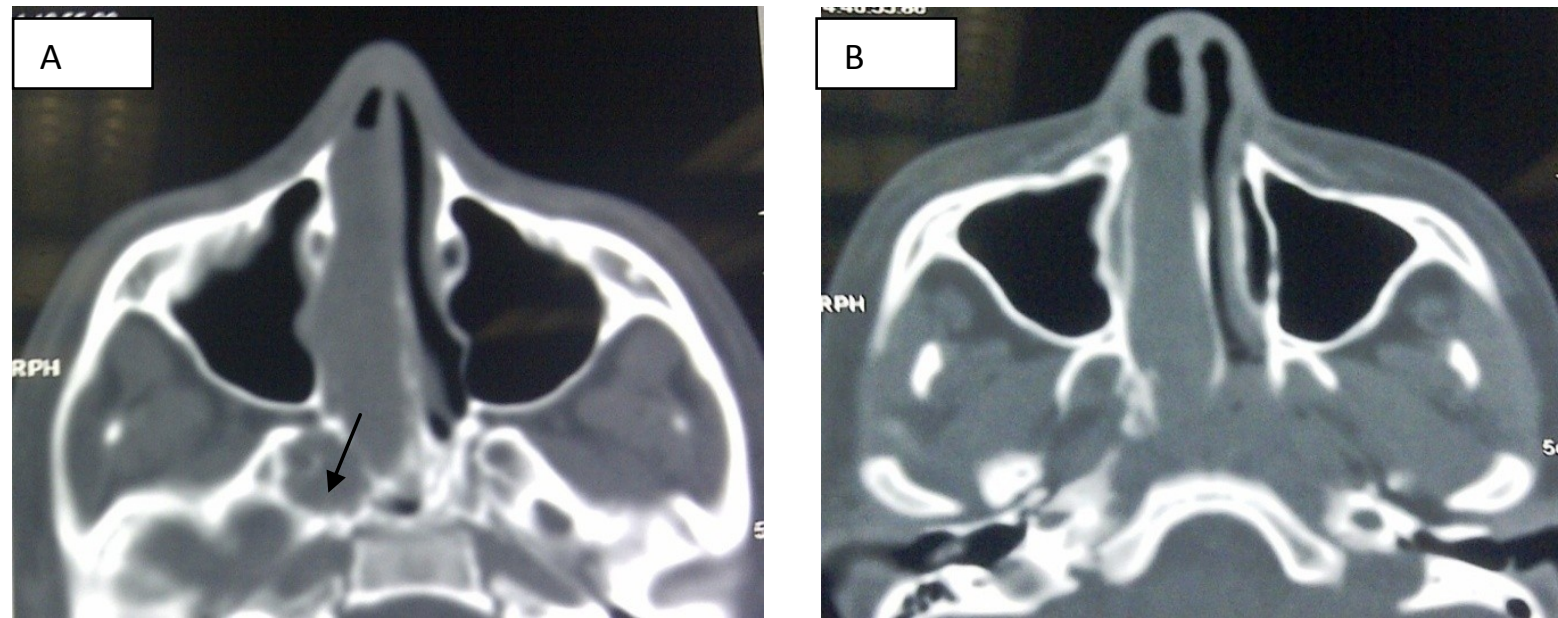

Figure 2 A\&B: Axial CT image: A. Tumor extends from th $\_$right pneumatised pterygoid air cell (the arrow) into nasopharynx and continuing into the nasal cavity on the right side. B. Tumor destructs the medial plate of pterygoid plate and continues into the nasal cavity on the right side 


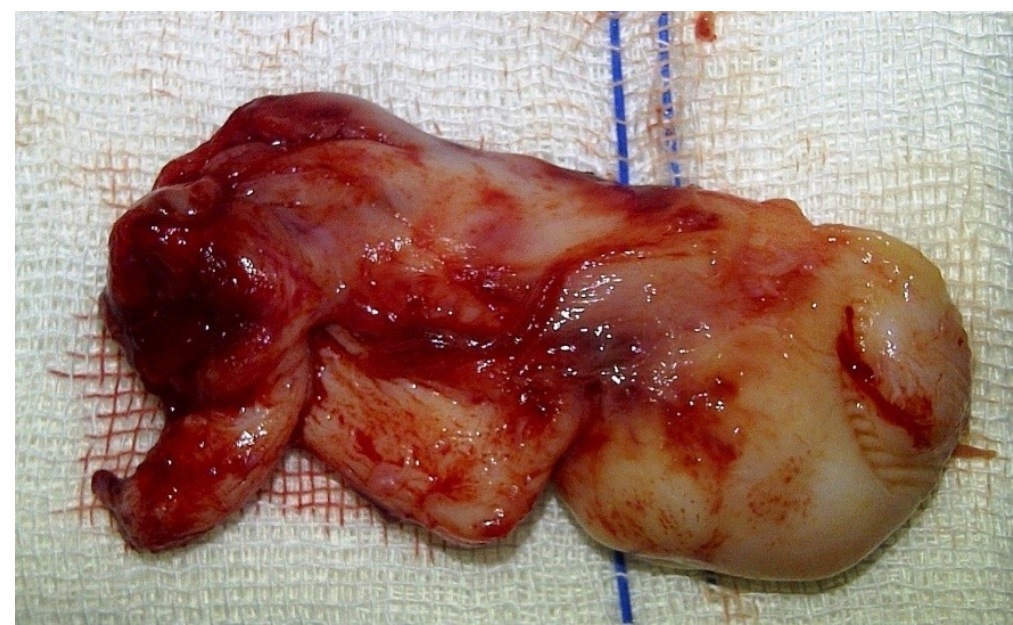

Figure 3: The mass after endoscopic removal of JAN

\section{Discussion}

Angiofibromas are histopathologically benign but potentially locally destructive vascular tumors. They are un-encapsulated neoplasms composed of a rich vascular network within a fibrous stroma ${ }^{10}$. Angiofibromas originate predominantly in the posterior-lateral wall of the nasopharynx. Angiofibromas arise typically in the nasopharynx, specifically at the trifurcation of the sphenoidal process of the palatine bone, the horizontal ala of the vomer, and the roof of the pterygoid process. These vascular tumors expand commonly beyond the nasopharynx into the cranium, nose, and paranasal sinuse ${ }^{11}$. Classically, JAF are confined to boys in adolescence and early adulthood. JNA accounts for less than $0.5 \%$ of all benign lesions that originate in the nasopharynx. JNA is an uncommon tumor, with reported incidence between 1 in 5000 and 1 in 60,000 otolaryngology patients $^{11,12 \text {, and } 13}$. In young adults, differential diagnosis of nasopharyngeal masses includes juvenile nasopharyngeal angiofibroma, meningoencephalocele, nasal glioma, hemangioma, grossly enlarged adenoids, and nasopharyngeal malignancies ${ }^{14,15}$.

Antrochoanal polyp (ACP) is a maxillary sinus polyp that originates in the maxillary sinus, passes through a sinus ostium and extends into the choana. ACPs represent approximately $4-6 \%$ of all nasal polyps in the general population ${ }^{16}$. The more common manifestation of Antrochoanal polyp is unilateral nasal obstruction, but it may sometimes be bilateral, depending upon the blockage of the nasopharynx ${ }^{17}$.

The more common manifestation of ACP is unilateral nasal obstruction (especially during the expiratory phase), but may sometimes be (20-25\% of cases) bilateral, depending upon the blockage of the nasopharynx. ${ }^{18}$

Other clinical manifestations are rhinorrhoea, bleeding, snoring, foreign body sensation, halitosis, headache, post nasal drip and loss of sense of smell. There are occasional reports of cases starting with epistaxis ${ }^{19}$, polyp strangulation ${ }^{20}$, spontaneous amputation ${ }^{21}$, dyspnoea and dysphagia ${ }^{22}$, with extension to the mouth producing dysphagia, speech disorders and obstructive sleep apnoea ${ }^{23}$.

In our case, the presentation was similar to that of antrochoanal polyp.

In a study of 72 patients, Lloyd et $\mathrm{al}^{2}{ }^{2}$ reported, three findings on CT and MR imaging that should suggest a diagnosis of JNA: (1) a soft tissue mass in the nasopharynx or nasal cavity, (2) a mass in the pterygopalatine fossa, (3) erosion of posterior osseous margin of the sphenopalatine foramen extending to the base of the medial pterygoid plate and Erosion and widening of vidian canal. ${ }^{2}$

In our case, the lesion was located in pneumatised ptyrygoid air cell with erosion of the base of the medial pterygoid plate and without erosion of posterior osseous margin of the sphenopalatine foramen, HolmanMiller sign or Widening of the sphenopalatine foramen.

\section{Conclusions}

A unilateral nasal polyp in childhood should not be taken lightly as an antrochoanal polyp, especially there is a juvenile nasopharyngeal angiofibroma mimicking an antrochoanal polyp.

\section{Reference}

[1]. Liu L, Wang R, Huang D, et al. Analysis of intra-operative bleeding and recurrence of juvenile nasopharyngeal angiofibromas. Clin Otolaryngol Allied Sci. 2002; 27:536-40.

[2]. Lloyd G, Howard D, Phelps P, et al. Juvenile angiofibroma: The lessons of 20 years of modern imaging. J Laryngol Otol. 1999; 113: $127-34$.

[3]. Mafee M: Imaging of the Nasal Cavities, Paranasal Sinuses, Nasopharynx, Orbits, Infratemporal Fossa, Pterygomaxillary Fissure, Parapharyngeal Space, and Base of the Skull, Snow Jr J.\& Ballenger J. editors: Ballenger's Otorhinolaryngology ,Head and Neck Surgery, 16'th ed., 2003,BC Decker Inc, chapter 31, p 654-707 
[4]. Topi MJ, Siniluoto MD, Jukka PL, Leinonen MD and Kalevi EJ. Value of pre-operative embolization in surgery for nasopharyngeal angiofibroma. J Laryngol Otol. 1993; 107: 514-21.

[5]. Nongrum HB, Thakar A, Gupta G, et al. Current Concepts in Juvenile Nasopharyngeal Angiofibroma. Journal of ENT Master class. 2009; 2: 88-95

[6]. Snyderman CH, Pant H, Carrau RL, et al. A New Endoscopic Staging System for Angiofibromas. Arch Otolaryngol Head Neck Surg. 2010; 136: 588-594.

[7]. Marshall AH, Bradley PJ. Management dilemmas in the treatment and follow-up of advanced juvenile nasopharyngeal angiofibroma. ORL J Otorhinolaryngol Relat Spec. 2006; 68:273- 8

[8]. Ahmad R, Ishlah W, Azilah N, Rahman JA. Surgical management of juvenile nasopharyngeal angiofibroma without angiographic embolization. Asian J Surg. 2008; 31:174-8.

[9]. Close LG, Schaefer SD, Mickey BE, Manning SC. Surgical management of nasopharyngeal angiofibroma involving the cavernous sinus. Arch Otolaryngol Head Neck Surg. 1989; 115:1091-5.

[10]. Huang RY, Damrose EJ, Blackwell KE, et al. Extranasopharyngeal angiofibroma. Int J Pediatr Otorhinolaryngol. 2000; 54: 59-64.

[11]. Herman P, Lot G, Chapot R, et al. Long-term followup of juvenile nasopharyngeal angiofibromas: analysis of recurrences. Laryngoscope. 1999; 109:140-7.

[12]. Tewfik TL, Tan AK, al Noury K, et al. Juvenile nasopharyngeal angiofibroma. J Otolaryngol. 1999; 28:145-51.

[13]. Choremis J, Frenkiel S. Juvenile nasopharyngeal angiofibroma in a 16 year-old male: diagnosis and surgical treatment. McGill Journal of Medicine (MJM). 1998; 4: 22-7.

[14]. Lee TJ, Huang SF. Endoscopic sinus surgery for antrochoanal polyps in children. Otolaryngol Head Neck Surg. 2006; 135: 688-92.

[15]. Durden DD. Skull Base tumor Surgery.Radiology of skull base neoplasms. Otolaryngol Clin North Am. 2001; 34: 1043-64.

[16]. El-Guindy A, Mansour MH. The role of transcanine surgery in antrochoanal polyp. J Laryngol Otol. 1994; 108:1055-7.

[17]. Frosini P, Picarella G, Casucci A. An unusual case of antrochoanal polyp with sudden laryngeal dyspnoea and stridor onset. Acta Otorhinolaryngol Ital. 2008; 298: 212-4.

[18]. Kamel R. Endoscopic transnasal surgery in antrochoanal polyps. Arch Otolaryngol Head Neck Surg 1990;116:841-3.

[19]. Robson AK, Barker CS, Whittet HB. Epistaxis as an unusual presentation of an antrochoanal polyp. J Laryngol Otol 1990; 104:6434.

[20]. Ole-Lengine L, Manni JJ. A strangulation antrochoanal polyp. A case report. J Laryngol Otol 1993; 107:342-3.

[21]. Rashid AM, Soosay G, Morgan D. Unusual presentation of a nasal (antrochoanal) polyp. Br J Clin Pract 1994; 48:108-9.

[22]. Grewal DS, Sharma BK. Dyspnea and dysphagia in a child due to an antrochoanal polyp. Auris Nasus Larynx 1984; 11:25-8

[23]. Sharma HS, Daud ARA. Antrochoanal polyp “a rare paediatric emergency”. Int J Pediatr Otorhinolaryngol 1997; 41:65-70. 